\title{
Numerical simulations on megathrust rupture stabilized under strong dilatancy strengthening in slow slip region
}

\author{
Yajing $\mathrm{Liu}^{1,2}$ \\ Received 15 February 2013; accepted 26 February 2013; published 15 April 2013.
}

[1] Episodic slow slip events (SSEs) typically involve a few millimeters to centimeters of slip over several days to months at depths near or further downdip of megathrust seismogenic zones. Despite its widespread presence in subduction margins, it remains unknown how SSEs interact with the seismogenic zone and affect megathrust ruptures. Here, I construct a 2-D thrust fault model governed by rate-state friction to investigate how fault dilatancy influences the amplitude and spatial distribution of ' coseismic slip, afterslip, and SSEs. Model results illustrate that, under strong dilatancy and high pore pressure around the friction stability transition, coseismic rupture stops at the onset of SSEs. Modeled SSEs have lower velocities, longer recurrence intervals and durations, and larger slip amounts as dilatancy becomes stronger, demonstrating a transition from short-term to long-term type of SSE behavior. These results qualitatively explain the range of spatial distributions of SSEs and megathrust ruptures observed or inferred in natural subduction zones. Furthermore, the relative depths of SSEs and megathrust afterslip may serve as an indicator of dilatancy effectiveness. Citation: Liu, Y. (2013), Numerical simulations on megathrust rupture stabilized under strong dilatancy strengthening in slow slip region, Geophys. Res. Lett., 40, 1311-1316, doi:10.1002/grl.50298.

\section{Introduction}

[2] Geodetic inversions have shown that most episodic slow slip events (SSE) in subduction zones take place near the end or further downdip from megathrust seismogenic zones [Dragert et al., 2001; McCaffrey et al., 2008; Beroza and Ide, 2011, and references therein]. In Cascadia and northern Hikurangi margins, where no great thrust earthquakes have been recorded in modern history, SSEs are distributed from partially locked to downdip free sliding regions [Dragert et al., 2001; McCaffrey et al., 2008], indicating that a potential megathrust rupture would likely stop before the end of SSE zone. In southwest Japan and Alaska subduction zones, SSEs seemed to abut the downdip ends of past megathrust rupture areas [Ide et al., 2007; Wei et al., 2012]. Modest spatial

\footnotetext{
All Supporting Information may be found in the online version of this article.

${ }^{1}$ Department of Earth and Planetary Sciences, McGill University, Montréal, Québec, Canada.

${ }^{2}$ Department of Geology and Geophysics, Woods Hole Oceanographic Institution, Woods Hole, Massachusetts, USA.
}

Corresponding author: Y. Liu, Department of Earth and Planetary Sciences, McGill University, 3450 University, 339 FD Adams, Montreal, Quebec, Canada. (yajing.liu@mcgill.ca)

(C)2013. American Geophysical Union. All Rights Reserved. 0094-8276/13/10.1002/grl.50298 overlap is also inferred between the slip areas of some SSEs and large thrust earthquakes in the Guerrero, Mexico, and Costa Rica subduction zones [Beroza and Ide, 2011]. In contrast, numerical models for the physical mechanism of spontaneous SSEs have predicted megathrust earthquakes would rupture the entire SSE zone and propagate further downdip, because the modeled SSEs nucleate near the downdip end but still within the seismogenic zone and often involve near-lithostatic pore pressure which facilitates coseismic rupture [Liu and Rice, 2007; Shibazaki and Shimamoto, 2007].

[3] Without introducing complex frictional property distributions such as a small stable-sliding patch embedded in the seismogenic zone, the above observations require that at least part of the SSE zone is frictionally unstable but can slip aseismically during earthquakes (Figure 1a). Fault gouge dilatancy appears to be a promising mechanism for stabilizing slip. For fluid-saturated compact granular materials, if dilatancy occurs more rapidly than pore fluid can flow into the newly created void space, local pore pressure is reduced and effective normal stress is increased, which stabilizes the shear slip and is called "dilatancy-strengthening". In particular, the stabilizing effect may become most significant at high pore pressure [Segall and Rice, 1995; Liu and Rubin, 2010; Segall et al., 2010], a condition implied at SSE depths in northern Cascadia and SW Japan [Shelly et al., 2007; Audet et al., 2009]. Motivated by the above observational and numerical findings, this study investigates how dilatancy-strengthening influences the amplitude of coseismic slip and the spatial distribution of megathrust ruptures, their afterslip and SSEs in the framework of rate and state-dependent friction.

\section{Model Setup and Parameters}

[4] Numerical simulations are performed to resolve a spectrum of deformation modes in subduction earthquake cycles using a quasi-dynamic computational approach as in previous studies [e.g., Liu and Rice, 2007]. The thrust fault dips at $12^{\circ}$ and is subject to a tectonic loading of $V_{\mathrm{pl}}=$ $37 \mathrm{~mm} / \mathrm{yr}$, representative of the convergence between the Juan de Fuca and North American plates in northern Cascadia. Shear stress $\tau$ is described by a single-state variable rate and state friction law [Dieterich, 1979; Ruina, 1983],

$$
\tau=\bar{\sigma} f=(\sigma-p)\left[f_{0}+a \ln \left(\frac{V}{V_{0}}\right)+b \ln \left(\frac{V_{0} \theta}{d_{c}}\right)\right],
$$

where $\bar{\sigma}$ is effective normal stress, $a$ and $b$ are rate and state stability parameters, $d_{c}$ is the characteristic slip distance over which state variable $\theta$ evolves after a velocity step, $V_{0}$ is a reference velocity, and $f_{0}$ is a nominal friction when $V=V_{0}$ at steady state. A regularized form of equation (1) is used at 
(a)
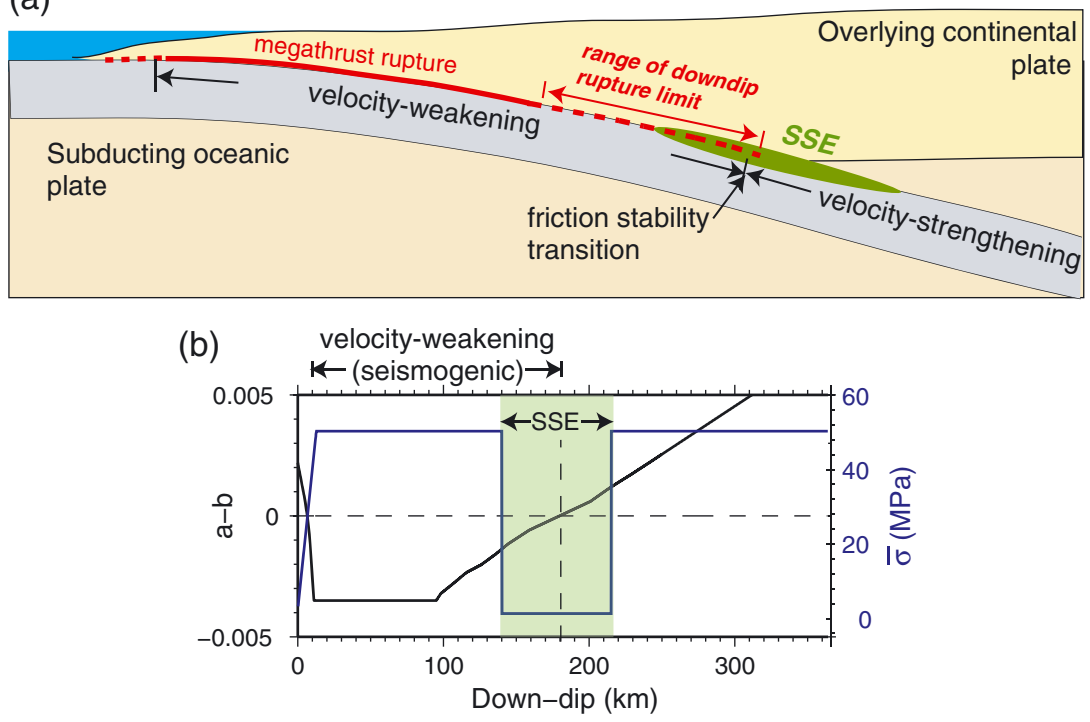

Figure 1. (a) Conceptual illustration of friction stability regimes, relative depths of slow slip events (SSE) (green), and megathrust ruptures (red) in subduction zones. (b) Friction parameter $a-b$ (black), effective normal stress $\bar{\sigma}$ (blue) for the reference model. $\bar{\sigma}=1 \mathrm{MPa}$ and $d_{c}=0.2 \mathrm{~mm}$ within 140-215 km defines the SSE zone.

small velocities [Rice et al., 2001]. State variable evolution follows the "ageing" law

$$
\frac{d \theta}{d t}=1-\frac{V \theta}{d_{c}} .
$$

Slip is stable when friction stability parameter $a-b>0$ (velocity-strengthening, VS) and may become unstable when $a-b<0$ (velocity-weakening, VW). Following Liu and Rice [2009], the depth distribution of $a-b$ (Figure 1b) is obtained by converting temperature-dependent gabbro gouge data [He et al., 2007] using a Cascadia subduction fault geotherm [Peacock, 2009]. The effective normal stress $\bar{\sigma}$ (Figure 1b) linearly increases with depth near the trench and is set to be a constant of $50 \mathrm{MPa}$ further downdip, except at a much lower level of 1-5 MPa near the VW-VS stability transition. The low $\bar{\sigma}$ zone is defined as the SSE region in this study. The characteristic slip distance $d_{c}$ is correspondingly small $(0.05-0.2 \mathrm{~mm})$ in the SSE zone, and is $11 \mathrm{~mm}$ on the rest of the fault. Supplementary Table S1 gives a complete list and description of model parameters.

[5] Fault gouge pore dilation and compaction are coupled to the rate and state framework, by assuming "membranediffusion" for pore pressure changes across the fault zone [Segall and Rice, 1995]. The pore pressure evolution follows

$$
\frac{d p}{d t}=-\frac{p-p_{0}}{t_{p}}+\frac{\epsilon}{\beta} \frac{1}{\theta} \frac{d \theta}{d t},
$$

where $p_{0}$ is a constant ambient pressure, $t_{p}$ is a characteristic diffusion time, $\epsilon$ is a dimensionless dilatancy coefficient and $\beta$ is the rock-pore bulk compressibility. A drainage parameter $U=t_{p} /\left(d_{c} / V_{\mathrm{pl}}\right)$ describes the relative timescales for pore fluid diffusion and friction evolution. In the range from intermediate to completely undrained conditions $(U=$ 0.01 to 10 ), the total coseismic slip and downdip rupture limit of the modeled earthquakes are similar to their reference values without dilatancy (Supplementary Figure S1). Thus, I focus on how variation in $\epsilon$, measured in the lab as the ratio between steady state gouge layer porosity change in response to sliding velocity steps [Samuelson et al., 2009], affects megathrust ruptures. Note that $\epsilon$ and $\beta$ enter equation (3) through the ratio $\epsilon / \beta$, which has the unit of pressure. Therefore, only $\epsilon / \beta$ is specified in the simulation. Laboratory measurements of $\epsilon$ are between $(0.1-3) \times 10^{-4}$ for quartz gouge, Westerly granite and clay-rich Ocean Drilling Program gouge [Marone et al., 1990; Samuelson et al., 2009, 2011]. With a bulk compressibility $\beta=5 \times$ $10^{-4} \mathrm{MPa}^{-1}$ [Segall and Rice, 1995], $\epsilon / \beta$ is within of 0.02 to $0.6 \mathrm{MPa}$.

[6] Equations (1)-(3) are coupled with the quasi-dynamic stress-slip relation to solve for slip, stress, and pore pressure evolution in earthquake cycles [Liu and Rubin, 2010]. A radiation damping term is introduced in the stress-slip relation to prevent slip velocity from going unbounded during instabilities. Given the same model parameters, this quasidynamic approximation produces earthquakes of the same spatial extent but lower slip velocities and rupture speeds compared to an elastodynamic approach [Lapusta and Rice, 2003]. Thus, it is an appropriate simplification for simulating the rupture spatial limit in this study.

\section{Results}

[7] As a reference model, Figure 2a shows a $~ 800$-year slip history without dilatancy. The maximum coseismic slip reaches $\sim 13 \mathrm{~m}$ and rupture propagates beyond the VW-VS transition before stopping at $\sim 230 \mathrm{~km}$. Figure $2 \mathrm{~b}$ shows the budget of different slip modes in an earthquake cycle. Coseismic slip accounts for all the slip in the fully locked zone and follows a near-linear decrease to zero at $230 \mathrm{~km}$. Afterslip starts to appear immediately downdip of the earthquake nucleation zone and reaches a peak where the coseismic slip terminates. In the 20 -year postseismic period, significant afterslip continues to accumulate downdip of the SSE region, while relatively small afterslip takes place in the SSE zone. Episodic SSEs occur spontaneously in the low $\bar{\sigma}$ zone in the interseismic periods, with an average interval of 1 to 1.5 years and maximum slip rates of $10^{2}$ to $10^{3} V_{\mathrm{pl}}$ 

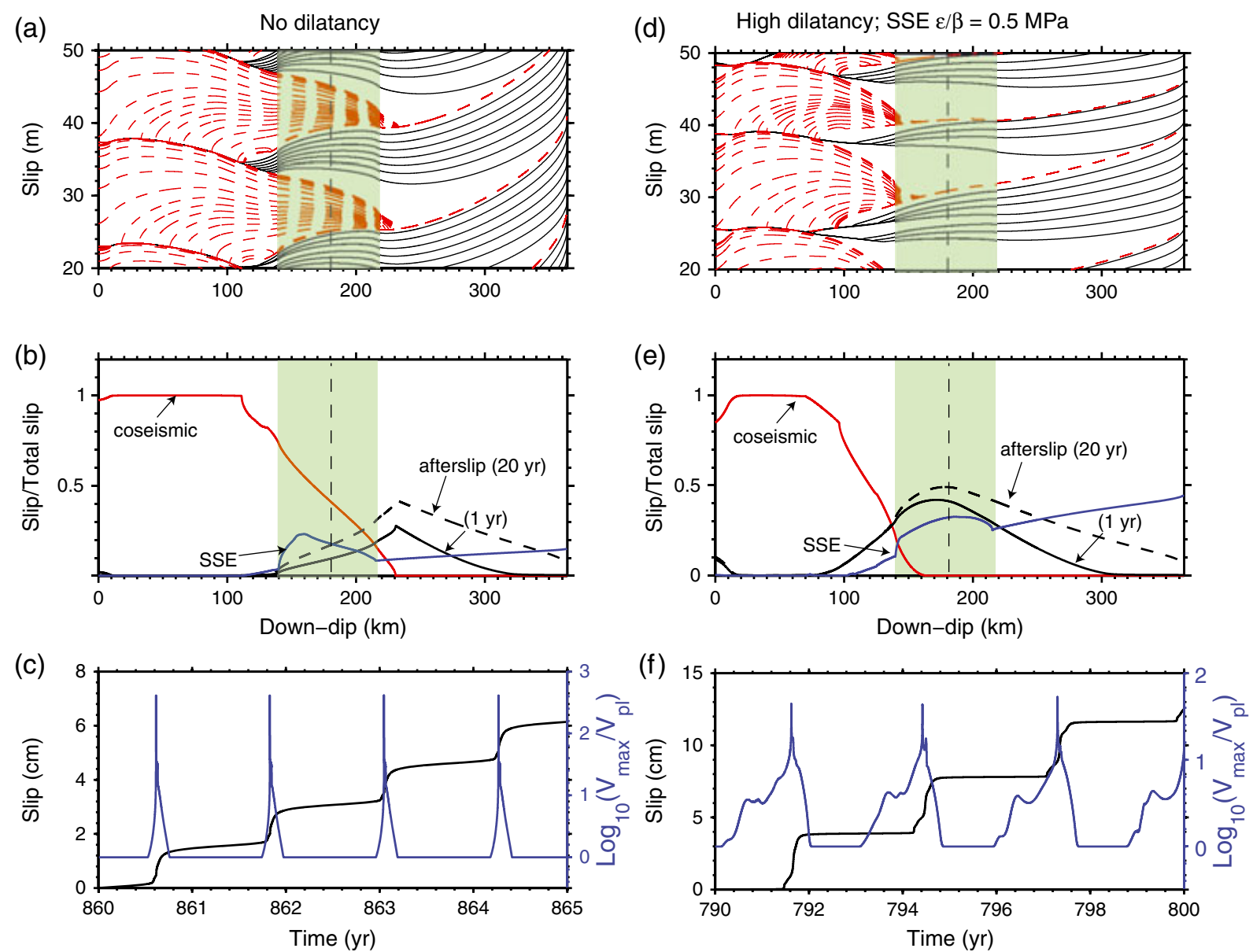

Figure 2. (a) Slip history on the fault during two earthquake cycles, (b) slip budget, and (c) cumulative slip and maximum slip rate, in $\log _{10}\left(V_{\max } / V_{\mathrm{pl}}\right)$, during four SSE episodes, of a reference model without dilatancy effect. $\bar{\sigma}=1 \mathrm{MPa}$ and $d_{c}=0.2 \mathrm{~mm}$ in the SSE zone. Figures 2(d)-2(e) are for a strong dilatancy case where $\epsilon / \beta=0.5 \mathrm{MPa}$ within the SSE zone and $0.1 \mathrm{MPa}$ on the rest of the fault. $\bar{\sigma}=2 \mathrm{MPa}$ and $d_{c}=0.05 \mathrm{~mm}$ in the SSE zone. $U=1$ at all depths. Black solid lines plot interseismic slip every 50 years. Red dashed lines plot coseismic slip every $20 \mathrm{~s}$. Slip becomes "coseismic" when $V_{\max }>5 \mathrm{~mm} / \mathrm{s}$. The total number of SSE episodes are 267 for the non-dilatancy case and 100 for the high dilatancy case. Non-zero SSE slip downdip from the SSE region is due to steady plate motion accumulated in the total SSE slip duration, defined when $V_{\max }>2 V_{\mathrm{pl}}$.

(Figure 2c). About $1.5 \mathrm{~cm}$ of slip is accumulated at $160 \mathrm{~km}$ within $\sim 0.15$ year. All the interseismic SSEs accommodate about $20 \%$ of the total slip.

[8] Dilatancy in the slow slip region can stop megathrust ruptures at shallower depths and result in different magnitude of coseismic slip than in the reference model. When the $\mathrm{SSE}$ region alone is under strong dilatancy $\epsilon / \beta=0.5 \mathrm{MPa}$ ( $0.1 \mathrm{MPa}$ on the rest of the fault), coseismic rupture stops at the onset of SSEs (Figure 2d). As shown in Figure 3a, for each fixed $(\epsilon / \beta)_{S Z}$, megathrust rupture terminates at a shallower depth as $(\epsilon / \beta)_{\mathrm{SSE}}$ increases. At $(\epsilon / \beta)_{S Z}=0.1 \mathrm{MPa}$, the downdip rupture limit rapidly decreases to near the updip of the SSE zone when $(\epsilon / \beta)_{\mathrm{SSE}}$ increases to $0.5 \mathrm{MPa}$ (Figure $3 b$ ). In natural subduction zones, both $\bar{\sigma}$ and $\epsilon / \beta$ may vary more gradually along the fault than the abrupt steps assumed here, implying that under strong dilatancy effect megathrust rupture could stop further updip from the SSE region and results in a spatial gap between the two deformation modes. The range of predicted relative distances is thus qualitatively consistent with the variations in natural subduction zones.
[9] The phase diagram of the maximum coseismic slip can be approximately divided into three regimes (Figure $3 \mathrm{c}$ ). In Regime I, $(\epsilon / \beta)_{S Z}<0.1 \mathrm{MPa}$ and $(\epsilon / \beta)_{\mathrm{SSE}}<0.2 \mathrm{MPa}$, coseismic slip can become much higher than its no dilatancy level, suggesting that dilatancy does not necessarily reduce earthquake slip. Gigantic earthquakes could slip nearly twice of the no dilatancy level due to the incomplete energy release by previous small earthquakes (Figure S2). In Regime II, $(\epsilon / \beta)_{S Z}<0.1 \mathrm{MPa}$ and $(\epsilon / \beta)_{\mathrm{SSE}}>0.2 \mathrm{MPa}$, coseismic slip remains relatively constant but slightly less than the no dilatancy value. In Regime III, $(\epsilon / \beta)_{S Z}>0.1 \mathrm{MPa}$, coseismic slip is independent to $(\epsilon / \beta)_{\mathrm{SSE}}$ but drops drastically with the increase of $(\epsilon / \beta)_{S Z}$. For $(\epsilon / \beta)_{S Z}>0.2 \mathrm{MPa}$, slip is aseismic everywhere on the fault, which agrees with the theoretical analysis of conditions for stable slip under dilatancy [Segall et al., 2010]. Therefore, it is dilatancy within the seismogenic zone itself, not of the SSE zone, that can significantly reduce the total coseismic slip.

[10] Dilatancy in the slow slip region also has profound influence on SSE properties. Figure 4 shows the dependence of SSE maximum slip velocity, slip amplitude 

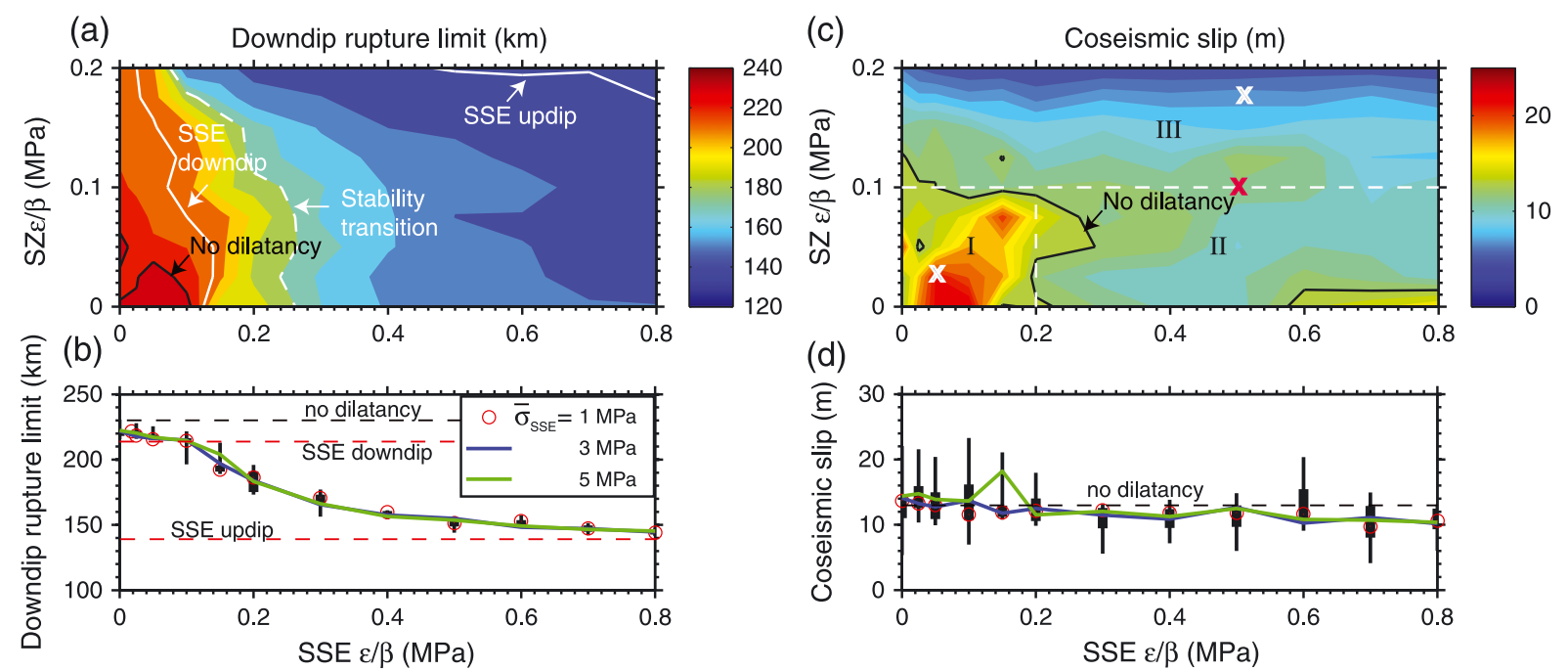

(d)

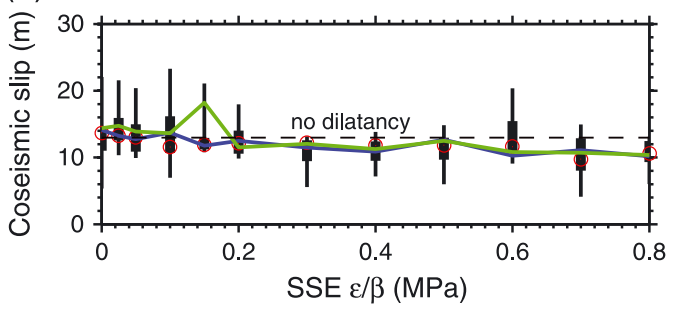

Figure 3. (a) Downdip rupture limit and (c) maximum coseismic slip dependence on $\epsilon / \beta$ in the seismogenic zone (SZ) and slow slip zone (SSE). Red cross is the case shown in Figures $2 d-2 f$. White crosses are cases shown in Supplementary Figures S3 and S4. Figures $2 \mathrm{~b}$ and $2 \mathrm{~d}:(\epsilon / \beta)_{S Z}=0.1 \mathrm{MPa}$. Thick and thin bars show 25-75 and 10-90 percentile, respectively. Median values for cases with $(\bar{\sigma})_{\mathrm{SSE}}=1,3$, and $5 \mathrm{MPa}$ are shown by red circles, blue, and green lines, respectively.

(a)

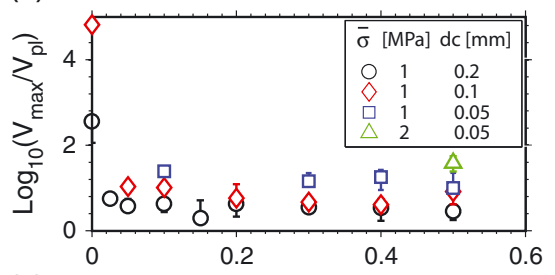

(c)

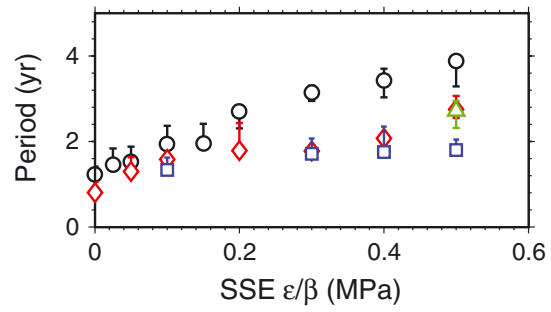

(b)

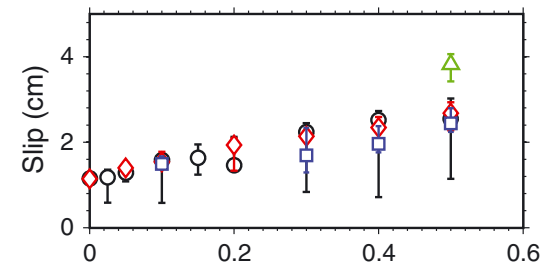

(d)

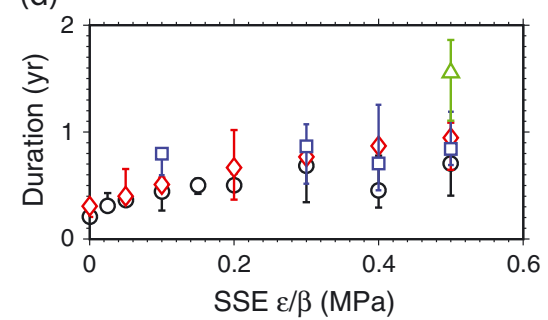

Figure 4. Dependence of SSE source properties (a) maximum slip velocity, (b) cumulative slip at the center of the VW SSE zone $(160 \mathrm{~km}),(\mathrm{c})$ recurrence period, and (d) duration on the dilatancy level $\epsilon / \beta$ in the SSE zone. The legend in Figure $4 \mathrm{a}$ shows four sets of $\bar{\sigma}(\mathrm{MPa})$ and $d_{c}(\mathrm{~mm})$ used in the SSE zone. Each point is computed from $\sim 100$ years of SSE sequences. The symbols represent the maximum likelihood values and the error bars represent the minimum and maximum ranges.

and duration, and recurrence period on the level of dilatancy in the SSE region. SSE velocity decreases by two orders of magnitude or more and remains between 2.5 to $100 V_{\mathrm{pl}}$ as $\epsilon / \beta$ becomes non-zero, consistent with previous studies [Liu and Rubin, 2010]. On the other hand, slip amplitude, duration, and recurrence period all increase with dilatancy. For the strong dilatancy case in Figure 2f, SSEs repeat every 3 years, each episode with an average slip of $4 \mathrm{~cm}$ and duration of 1.5 years. The range of SSE properties under strong dilatancy are similar to the long-term SSEs observed in Tokai and Bungo Channel, SW Japan [Hirose and Obara, 2005; Miyazaki et al., 2006].

\section{Discussion}

[11] In this study simulations using different levels of $\bar{\sigma}_{S S E}$ $(1,3$, and $5 \mathrm{MPa})$ result in essentially the same downdip rupture limit and maximum coseismic slip (Figures $3 \mathrm{~b}$ and $3 \mathrm{~d})$. This implies the level of $\bar{\sigma}_{\mathrm{SSE}}$, at least in a range that produces SSEs with recurrence intervals (1-5 years), does not affect the megathrust downdip rupture limit. Thus, although the present model is constructed using a Cascadialike geometry and geotherm, it can also be applied to assess the dilatancy effect in other subduction zones where different SSE intervals may indicate different effective normal stresses [Liu and Rice, 2007]. 
[12] From a slip budget perspective, the relative depth distribution and amplitude of SSEs and afterslip exhibit distinctive features as dilatancy varies (Figures $2 \mathrm{~b}$ and $2 \mathrm{e}$ ). With none or low dilatancy effect, the peak of afterslip is reached downdip of the SSEs, whereas at high dilatancy, large afterslip spatially overlap with SSEs. Furthermore, at high dilatancy, a larger amount of afterslip $(\sim 50 \%)$ is accumulated in the first postseismic year, in contrast to $\sim 30 \%$ at none or low dilatancy. Such relative depth and amplitude distributions of afterslip and SSEs, if available from seismic and geodetic inversions, would be valuable indicators for whether dilatancy is indeed effective in the slow slip region and thus shed lights on potential rupture extent. The longterm SSEs in Bungo Channel are in the depth range where the afterslip of the 1946 Nankai megathrust earthquake took place, and the mainshock rupture was updip from both the afterslip and SSEs [Sagiya and Thatcher, 1999; Hirose and Obara, 2005]. The complementary distribution of coseismic, afterslip, and SSEs there is qualitatively consistent with the model predictions under high dilatancy. Similarly, geodetic inversions have suggested the postseismic slip of the 1964 Alaska megathrust earthquake and recent slow slip events took place downdip from its central and northern rupture area [Wei et al., 2012]. We do note that the 1946 Nankai Trough coseismic slip model derived from the leveling survey [Sagiya and Thatcher, 1999] may contain some afterslip signature, which if subtracted would result in shallower coseismic slip and hence a "gap" in depth to SSEs. In our current model, for simplicity, the high dilatancy zone coincides with the SSE region, which dictates that megathrust ruptures always stop just updip of the SSE zone under strong dilatancy. A spatial "gap" could be realized by prescribing high dilatancy in a depth range immediately updip of the SSE zone.

[13] The transition from short-term to long-term SSEs behavior as dilatancy increases (Figure 4) provides insights to constructing a model that can produce both types of SSEs simultaneously with properties similar to those observed in Tokai and Bungo Channel [Hirose and Obara, 2005; Miyazaki et al., 2006; Matsuzawa et al., 2010]. For example, if strong dilatancy is limited to the updip portion of the SSE zone while the rest of the SSE zone remains under low dilatancy, it is possible to produce less frequent, slower slipping long-term SSEs in the updip part and more frequent, faster slipping short-term SSEs in the downdip part. Short-term SSEs may overlap spatially and temporally with long-term SSEs. One such example is shown in Supplementary Figure S5. However, it is beyond the scope of this study to introduce more heterogeneous frictional and hydraulic properties on the fault to quantitatively match various aspects long-term and short-term SSE observations.

[14] The current model does not incorporate the effect of shear heating induced thermal pressurization [Rice, 2006; Segall and Bradley, 2012], which is a weakening mechanism particularly effective under fast shear rates. However, thermal pressurization alone would lead to higher seismic velocity, faster propagation speed and consequently more seismic slip in the SSE and further downdip stablesliding region, which is opposite to the observations in many subduction zones. It remains to be explored how megathrust earthquake characteristics and potential interaction with SSEs are affected under the competition between dilatancy strengthening and thermal pressurization mechanisms.

\section{Conclusion}

[15] In summary, our numerical results illustrate that dilatancy-strengthening in the slow slip region is an effective mechanism for damping or completely stopping the downdip propagation of megathrust rupture. Under strong dilatancy and near-lithostatic pore pressure around the VWVS friction stability transition, megathrust rupture stops at the onset of SSEs. A range of downdip rupture limit can be predicted under different levels of dilatancy, which is represented by a dilatancy parameter $\epsilon / \beta$ with values estimated from available lab experiment data. Modeled episodic slow slip events have much lower slip velocity, longer duration, and larger slip amount, longer recurrence interval as dilatancy effect becomes stronger, demonstrating a transition from short-term to long-term type of SSE behavior. These results qualitatively explain the range of spatial distributions of SSEs and megathrust rupture areas observed or inferred in natural subduction zones, without arbitrarily introducing a stable-sliding segment in the seismogenic zone. The distinctive depth and amplitude of SSEs and afterslip may serve as an indicator for the importance of dilatancy on a subduction fault. The total coseismic slip is significantly reduced under high dilatancy in the updip seismogenic zone. The potential damage by a megathrust earthquake, which is affected by both the amount and spatial extent of the coseismic slip, could thus be mitigated by the operation of dilatancy in both the seismogenic and SSE regions.

[16] Acknowledgments. I thank Jim Rice, Allan Rubin and Jeff McGuire for discussion during the manuscript preparation. Review comments from Paul Segall and an anonymous reviewer helped to improve the presentation. This work was supported by NSF-EAR award 1015221 to Liu at WHOI and a NSERC Discovery Grant to Liu at McGill.

\section{References}

Audet, P., M. G. Bostock, N. I. Christensen, and S. M. Peacock (2009), Seismic evidence for overpressured subducted oceanic crust and megathrust fault sealing, Nature, 457, 76-78, doi: 10.1038/nature 07650 .

Beroza, G. C., and S. Ide (2011), Slow earthquakes and nonvolcanic tremors, Annu. Rev. Earth Planet. Sci., 39, 271-296, doi: 10.1146/annurev-earth-040809-152531.

Dieterich, J. H. (1979), Modeling of rock friction 1. Experimental results and constitutive equations, J. Geophys. Res., 84(B5), 2161-2168.

Dragert, H., K. Wang, and T. S. James (2001), A silent slip event on the deeper Cascadia subduction interface, Science, 292(5521), 1525-1528.

He, C., Z. Wang, and W. Yao (2007), Frictional sliding of gabbro gouge under hydrothermal conditions, Tectonophys., 445, 353-362, doi: 10.1016/j.tecto.2007.09.008.

Hirose, H., and K. Obara (2005), Repeating short- and long-term slow slip events with deep tremor activity around the Bungo channel region, southwest Japan, Earth. Planets. Space, 57(10), 961-972.

Ide, S., D. R. Shelly, and G. C. Beroza (2007), Mechanism of deep low frequency earthquakes: Further evidence that deep non-volcanic tremor is generated by shear slip on the plate interface, Geophys. Res. Lett., 34, L03308, doi: 10.1029/2006GL028890.

Lapusta, N., and J. R. Rice (2003), Nucleation and early seismic propagation of small and large events in a crustal earthquake model, J. Geophys. Res. Solid Earth, 108(B4), doi: 10.1029/2001JB000793.

Liu, Y., and J. R. Rice (2007), Spontaneous and triggered aseismic deformation transients in a subduction fault model, J. Geophys. Res., 112, B09404, doi: 10.1029/2007JB004930.

Liu, Y., and J. R. Rice (2009), Slow slip predictions based on granite and gabbro friction data compared to GPS measurements in northern Cascadia, J. Geophys. Res., 114, B09407, doi: 10.1029/2008JB006142.

Liu, Y., and A. M. Rubin (2010), Role of fault gouge dilatancy on aseismic deformation transients, J. Geophys. Res., 115, B10414, doi: 10.1029/2010JB007522.

Marone, C., C. B. Raleigh, and C. H. Scholz (1990), Frictional behavior and constitutive modeling of simulated fault gouge, J. Geophys. Res., 95 (B5), 7007-7025.

Matsuzawa, T., H. Hirose, B. Shibazaki, and K. Obara (2010), Modeling short- and long-term slow slip events in the seismic cycles of 


\section{LIU: DILATANCY EFFECTS ON THRUST EARTHQUAKES}

large subduction earthquakes, J. Geophys. Res., 115. B12301, doi: 10.1029/2010JB007566.

McCaffrey, R., L. M. Wallace, and J. Beavan (2008), Slow slip and frictional transition at low temperature at the Hikurangi subduction zone, Nature, Geosci., 1, 316-320.

Miyazaki, S., P. Segall, J. J. Mcguire, T. Kato, and Y. Hatanaka (2006), Spatial and temporal evolution of stress and slip rate during the 2000 Tokai slow earthquake, J. Geophys. Res., 111 (B3), B03409, doi: $10.1029 / 2004 J B 003426$.

Peacock, S. M. (2009), Thermal and metamorphic environment of subduction zone episodic tremor and slip, J. Geophys. Res., 114, B00A07, doi: 10.1029/2008JB005978.

Rice, J. R. (2006), Heating and weakening of faults during earthquake slip, J. Geophys. Res., 111, B05311, doi:10.1029/2005JB004006.

Rice, J. R., N. Lapusta, and K. Ranjith (2001), Rate and state dependent friction and the stability of sliding between elastically deformable solids, J. Mech. Phys. Solids, 49, 1865-1898.

Ruina, A. L. (1983), Slip instability and state variable friction laws, $J$. Geophys. Res., 88(B12), 10,359-10, 370.

Sagiya, T., and W. Thatcher (1999), Coseismic slip resolution along a plate boundary megathrust: The Nankai Trough, southwest Japan, J. Geophys. Res., 104(B1), 1111-1129, doi:10.1029/98JB02644.

Samuelson, J., D. Elsworth, and C. Marone (2009), Shear-induced dilatancy of fluid saturated faults: Experiment and theory, J. Geophys. Res., 114, B12404, doi:10.1029/2008JB006273.
Samuelson, J., D. Elsworth, and C. Marone (2011), Influence of dilatancy on the frictional constitutive behavior of a saturated fault zone under a variety of drainage conditions, J. Geophys. Res., 116, B10406, doi: $10.1029 / 2011$ JB008556.

Segall, P., and M. Bradley (2012), The role of thermal pressurization and dilatancy in controlling the rate of fault slip, J. Appl. Mech., 79, 031013, doi:10.1115/1.4005896.

Segall, P., and J. R. Rice (1995), Dilatancy, compaction, and slip instability of a fluid-infiltrated fault, J. Geophys. Res., 100(B11), 22,155-22,171.

Segall, P., A. M. Rubin, M. Bradley, and J. R. Rice (2010), Dilatant strengthening as a mechanism for slow slip events, J. Geophys. Res., 115, B12305, doi:10.1029/2010JB007449.

Shelly, D. R., G. C. Beroza, and S. Ide (2007), Non-volcanic tremor and low-frequency earthquake swarms, Nature, 305-307, doi:10.1038/nature 05666.

Shibazaki, B., and T. Shimamoto (2007), Modelling of short-interval silent slip events in deeper subduction interfaces considering the frictional properties at the unstable-stable transition regime, Geophys. J. Int., 171 (1), 191-205, doi:10.1111/j.1365-246X.2007.03434.X.

Wei, M., J. J. McGuire, and E. Richardson (2012), A slow slip event in the south central Alaska subduction zone and related seismicity anomaly, Geophys. Res. Lett., 39, L15309, doi:10.1029/2012GL 052351 . 